\title{
RECUPERAÇÃO DA ÁREA DEGRADADA DO \\ CERCADINHO ATRAVÉS DO PLANTIO DE PLANTAS COM RAÍZES FORTES
}

Samira Avelar Ventura Felipe - samiraavelar@ hotmail.com

Centro Universitário de Belo Horizonte

Lílian Mendes de Almeida - lilianmendesdealmeida@gmail.com

Centro Universitário de Belo Horizonte

Lorena Roberta Garcia Maciel - lorenaroberta_2006@hotmail.com

Centro Universitário de Belo Horizonte

Nayara de Oliveira Pereira - nayoliver06@gmail.com

Centro Universitário de Belo Horizonte

Thiago Guimarães Alvim - thiago_alvim@msn.com

Centro Universitário de Belo Horizonte 


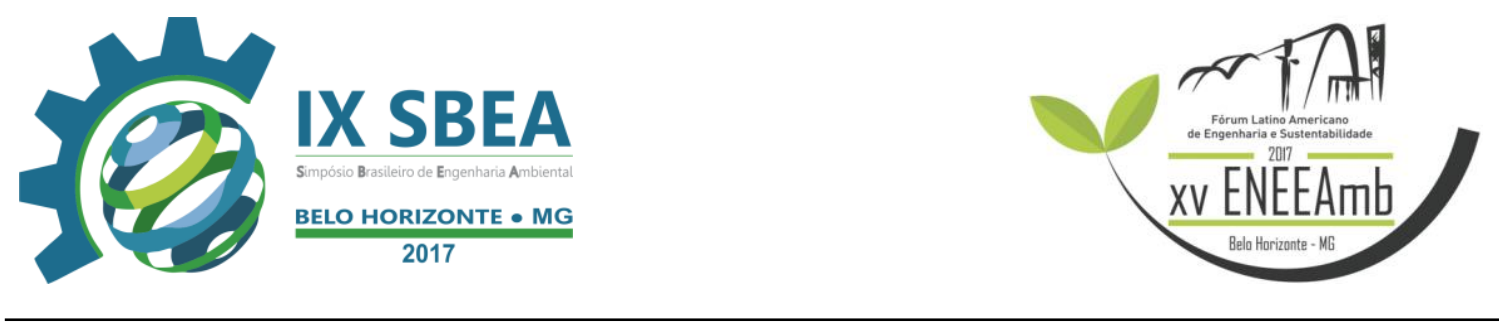

\section{RESUMO}

Considerando o intenso processo de urbanização que vem acontecendo no Brasil nas últimas décadas, em decorrência do crescimento populacional desenfreado, as grandes metrópoles apresentado o surgimento de favelas, aglomerados, vilas em grandes proporções, principalmente no entorno dos mananciais, gerando assim grandes impactos negativos ao meio ambiente. Em Minas Gerais, na região oeste de Belo Horizonte, existe a comunidade Ventosa que também não foge deste intenso processo, onde o crescimento irregular teve como principal instalação o córrego Cercadinho, que abastece não só essa comunidade, mas bairros de classe média em torno, as pessoas que moram nesse lugar são menos desfavorecidas, pois, a quantidade de lixo e resíduos sólidos são de nível elevado. Sendo assim, foram realizados estudos que caracterizam a área de ocupação desordenada, diagnosticando as fontes de poluentes no corpo hídrico, pontuais e difusas, que causam impactos socioambientais significativos. Com base neste estudo, foi analisado os impactos causados ao córrego Cercadinho como a contaminação, decorrente da ação antrópica, da falta de instrução da população e do descaso do Poder Público mediante a ocupação irregular. Fazem-se necessárias a conscientização da população no que diz a respeito sobre o meio ambiente e como preserva-lo, promovendo a renovação da percepção dos indivíduos perante o mundo e perante a convivência uns com os outros. Cabe ao Poder Público investir na revitalização do córrego e da comunidade inserindo no contexto os moradores, para que tenham participação efetiva valorizando e preservando os recursos naturais.

Palavras-chave: urbanização, favelização, impactos, meio ambiente, crescimento desordenado, conscientização, educação ambiental, revitalização, preservar.

\section{INTRODUÇÃO/OBJETIVO}

De acordo com o IBGE (Instituto Brasileiro de Geografia e Estatística) a população brasileira estava em cerca de 195,7 milhões em 2010. O censo de 2010 ainda aponta a quantidade de residências caracterizadas como aglomerados subnormais em cerca de 56 milhões, representando $22 \%$ da população brasileira vivendo em áreas de vilas e favelas.

Segundo a URBEL (Companhia Urbanizadora e de Habitação de Belo Horizonte), Belo Horizonte possui 2.412.937 habitantes, destes, cerca de 460 mil moradores, ou seja, $22 \%$ da população são moradores de áreas irregulares, conjuntos habitacionais, vilas e favelas. Em Belo Horizonte nos últimos 4 anos, surgiram novos assentamentos e ocupações irregulares. 


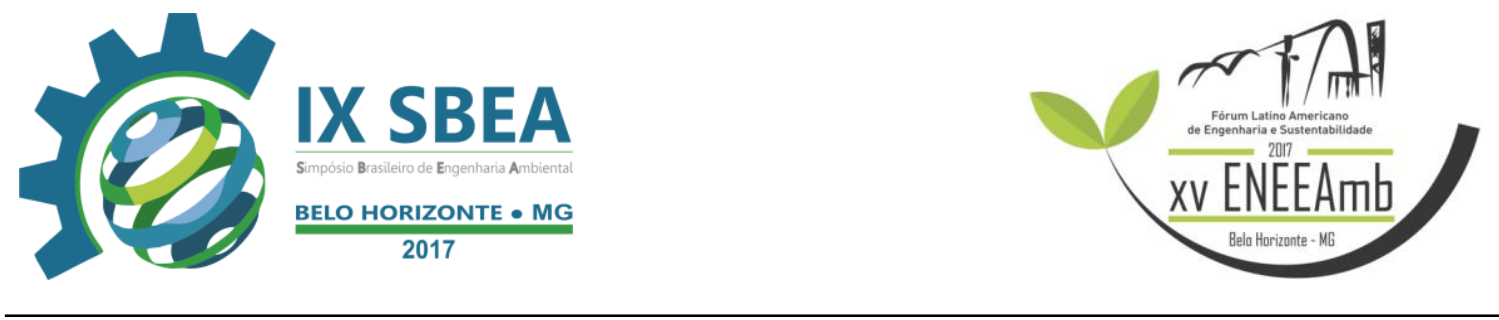

Historicamente as vilas e favelas no Brasil são antigas, surgindo primeiramente na época da abolição da escravatura quando parte dos negros foram obrigados a deixar a residência de seus senhores, refugiando-se assim em quilombos, o que deu origem nas atuais favelas do Brasil. Eram locais de refúgio, única oportunidade própria mediante a dificuldade de aquisição causada pela especulação imobiliária, falta de planejamento urbano e políticas públicas eficientes, ou seja, várias variáveis de cunho social, financeiro, político e cultural.

A maioria de favelas e aglomerados se desenvolveu perto ou envolta de córregos, para que tivesse maior facilidade de acesso à água, já que a maioria das casas não possui saneamento básico.

O crescimento da demanda mundial de água com parâmetros de qualidade aceitável, comparado com a demanda do ritmo de sua renovação de seu ciclo natural hidrológico, causa preocupação pela sua disponibilidade em vista que a qualidade e quantidade da água é um recurso de vital importância para os seres humanos e para o meio ambiente, portanto, está sendo realizado um estudo que identifica a qualidade da água do córrego Cercadinho. Será realizada uma análise para verificar a qualidade da água e do solo de acordo com alguns parâmetros descritos a seguir.

A resolução do Conselho Nacional do Meio Ambiente - CONAMA n ${ }^{\circ}$ 357/2005 estabelece as classes de qualidade para as águas salobras, doces e salinas. As classes definem padrões para parâmetros físicos, químicos e biológicos da água de acordo com a exigência para seu uso.As águas de classe especial devem ter sua condição natural, não podendo haver lançamentos de efluentes, mesmo que tratados. Para as demais classes, são aceitáveis níveis crescentes de poluição, sendo que a classe 1 é a que possui os menores níveis e a classe 4 os maiores níveis de poluição.

Destinação da água de cada classe:

Especial: Abastecimento doméstico sem qualquer tipo de desinfecção; Preservação do equilíbrio natural das comunidades aquáticas.

Classe 1: Abastecimento doméstico com tratamento simples; Aquicultura; Recreação Primaria (Natação, mergulho); Irrigação da Horta.

Classe 2: Abastecimento doméstico com tratamento convencional; Aquicultura; Irrigação de Hortas e plantas frutíferas

Classe 3: Abastecimento doméstico com tratamento convencional; Dessedentação de animais

Classe 4: Harmonia paisagística; Usos menos exigentes.

De tal maneira que o presente artigo tem como objetivo caracterizar a área de estudo, apresentando seu histórico de evolução, diagnosticando os aspectos e impactos que ocorrem na área de estudo, através de uma análise de água e solo após resultados obtidos propor medidas de conscientização para a população que habita próximo dessa região e fazer um estudo de área para que possa ser plantada plantas de raízes fortes 


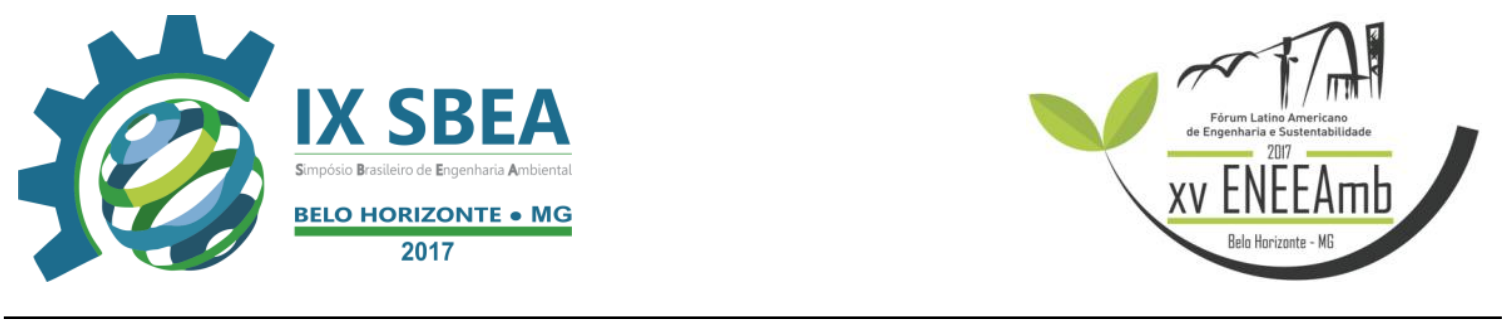

para ajudar e evitar o desmoronamento dessa área que sofre muitos riscos, tanto para o meio ambiente que já está desgastado e para a população que lá vive

\section{METODOLOGIA}

Para cumprimento deste artigo, foram realizadas diversas etapas, visando à interligação dos dados e resultados obtidos no decorrer da elaboração do mesmo.

Para tal foram cumpridas as seguintes etapas:

Revisão bibliográfica acerca do tema proposto por meio de artigo científicos, relatórios, revistas, sites governamentais e relacionados ao sistema hídrico, urbanização e problemas decorrentes de ocupação irregular.

Análise da qualidade da água, afim de, identificar os aspectos levantados no decorrer do artigo nos quais afetam diretamente a qualidade da água de acordo com a legislação vigente, o qual foi verificado em quais parâmetros a água do local se encontra;

Com o intuito de quantificar os aspectos e os impactos gerados pela ocupação irregular, foi realizado visitas ao local e questionários com moradores daquela região;

Aplicação do questionário amostral aos moradores da região do córrego Cercadinho afim de, quantificar grau de instrução, rede de saneamento básico e relatos de enchentes e alagamentos, além da importância que o córrego possui a comunidade;

Ação educacional com participação da comunidade interagindo com meio ambiente, afim de, conscientizar os moradores do local a preservação do Córrego Acaba através de cartilhas informativas e educativas.

\section{RESULTADOS E DISCUSSÃO}

A área de estudo fica situada no estado de Minas Gerais, na cidade de Belo Horizonte onde predomina o bioma Cerrado e Mata Atlântica com território aproximadamente $331.401 \mathrm{Km}^{2}$, o estudo ocorre precisamente na região Oeste da capital entre os bairros Buritis e Estoril, Havaí e São José. Segundo dados do Censo Demográfico (2000), a Região Oeste, onde se encontra o Córrego Cercadinho possui uma área de $31.27 \mathrm{~m}^{2}$, com aproximadamente 268.124 habitantes, como mostra a Figura 1 

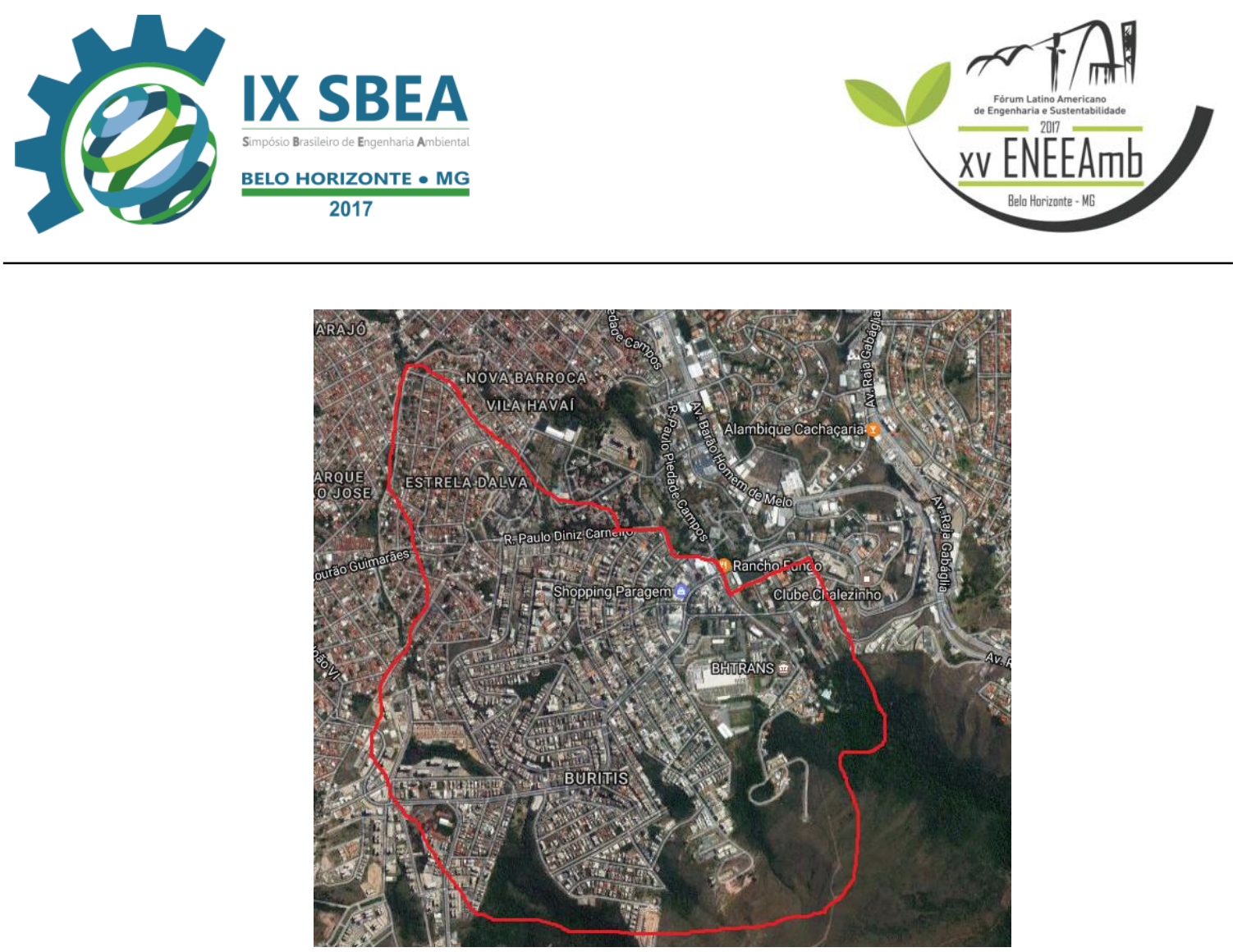

Figura 1: Área de Estudo - Região Oeste de Belo Horizonte / Fonte: Google Earth (2017).

A região apresenta-se, ainda, bairros como Buritis e Estoril que apresentam áreas de expansão urbana. A topografia da região é muito acidentada, apresentando raros e descontínuos trechos de declividade suave, destacando como local mais acidentado da região, o aglomerado Morro das Pedras.

A área hoje ocupada pelo bairro Buritis, era, até o início da década de 70 uma fazenda uma fazenda particular e por volta de 1973 esta fazenda começou a ser desmembrada e terrenos menores começaram a ser vendidos. Havia apenas uma via de acesso para a região, a Rua D. João VI, que se ligava ao Anel Rodoviário próximo à estação da Cemig. A região era considerada Zona Rural.

No início da década de 80, foram implantadas as principais ruas do bairro e a ligação com a Avenida Raja Gabaglia. Na época o bairro era habitado por apenas algumas dezenas de moradores e meio isolado da cidade, o Buritis assim permaneceu por vários anos, até que em 1988, o quadro passou a se modificar.

O presente artigo apresenta dados obtidos por meio de questionário aplicado aos moradores dos Bairros da Região Oeste e informações retiradas do censo demográfico IBGE no ano 2005 a 2014, no qual foi extraído o número de habitantes, área territorial e histórico urbano. Contudo foram realizadas várias visitas técnicas aos bairros, no qual as primeiras visitas tiveram um maior foco em conhecer o local a ser estudado, com registros fotográficos e entrevistas com moradores da região, as demais visitas tiveram como objetivo a coleta da água para análise de qualidade por meio de testes físico-químicos e aplicação do questionário com perguntas fundamentais, com intuito de verificar a interação entre o Córrego Cercadinho e comunidade. 


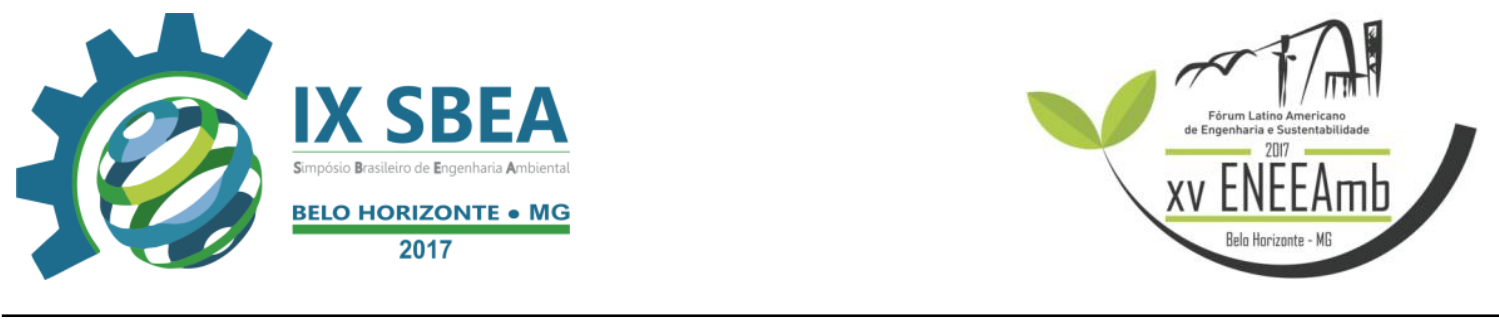

Com os dados obtidos ao longo das visitas de campo, foi confeccionado um check-list levantado os aspectos ambientais do local e quais impactos causados pelo mesmo de acordo com a tabela abaixo.

\begin{tabular}{|c|c|}
\hline \multicolumn{2}{|c|}{$\begin{array}{c}\text { CHECKLIST - Redondezas do Córrego Cercadinho, Região } \\
\text { Oeste de Belo Horizonte - MG. }\end{array}$} \\
\hline ASPECTOS AMBIENTAIS & IMPACTOS AMBIENTAIS \\
\hline Ocupações irregulares & $\begin{array}{l}\text { Desnudamento do solo e } \\
\text { redução da biota }\end{array}$ \\
\hline $\begin{array}{l}\text { Descarte irregular de } \\
\text { resíduos e matéria orgânica }\end{array}$ & $\begin{array}{c}\text { Aumento de risco de animais } \\
\text { peçonhentos e/ou vetores de } \\
\text { doenças }\end{array}$ \\
\hline Atividades minerária & $\begin{array}{l}\text { Aumento da erosão, ruídos e } \\
\text { aumento das doenças } \\
\text { respiratórias. }\end{array}$ \\
\hline Impermeabilização do solo & Compactação do solo \\
\hline $\begin{array}{l}\text { Descarte de resíduos em } \\
\text { curso d' água }\end{array}$ & $\begin{array}{l}\text { Depreciação da qualidade da } \\
\text { água, contaminação do corpo } \\
\text { hídrico. }\end{array}$ \\
\hline $\begin{array}{l}\text { Descarte irregular de } \\
\text { resíduos sólidos, líquidos e } \\
\text { óleos }\end{array}$ & Turbidez da água \\
\hline $\begin{array}{l}\text { Canalização de esgoto } \\
\text { doméstico disposta no } \\
\text { córrego }\end{array}$ & Poluição dos recursos hídricos \\
\hline Canalização do córrego & Enchentes e alagamentos \\
\hline
\end{tabular}

Tabela 1 - Aspectos ambientais do local.

Um dos grandes problemas enfrentados pelos bairros próximos ao Córrego Cercadinho é a sua poluição, devido ao descarte incorreto dos resíduos sólidos e lançamento de esgoto doméstico sem tratamento, ao longo do curso d'água, ocasionando uma série de problemas, como inundações, enchentes e outros diversos malefícios podendo assim afetar a saúde dos moradores da região. Outro problema levantado na comunidade é a impermeabilização do solo, que dificulta a capacidade de infiltração natural da água contribuindo ainda mais para que ocorram alagamentos em período chuvoso.

Diagnosticados os problemas, o presente artigo tem com foco conscientizar os moradores da região por meio de cartilhas educativas sobre o descarte incorreto de 


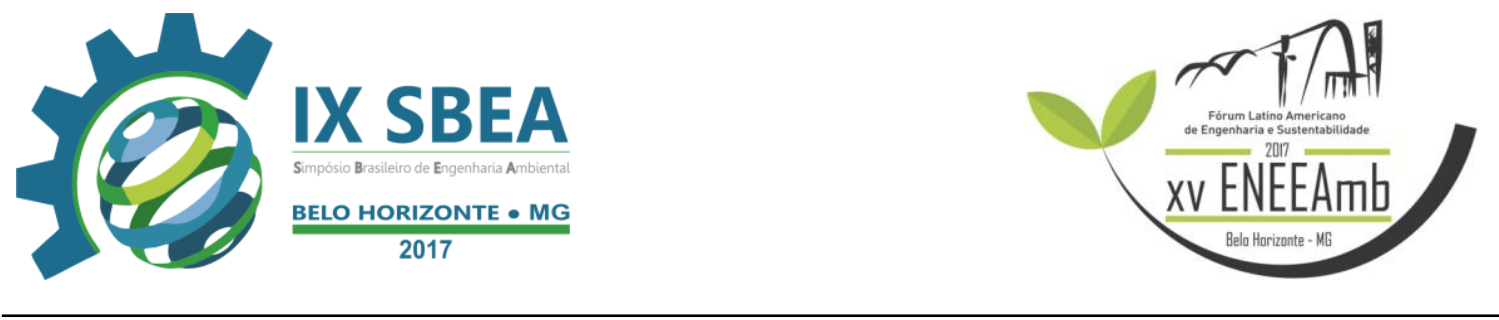

resíduos, além de propor algumas diretrizes que amenizem ou extinguem os danos causados, de acordo com o que estabelece o plano diretor de Belo Horizonte, lei $\mathrm{n}^{\mathrm{o}}$ 7.165/96, regulamenta que o meio ambiente é o conjunto de condições, Leis, influências e interações de ordem física, química, biológica, social, cultural e política que permite, abriga e rege a vida em todas suas formas. (BARBOSA,2011).

Portanto, é estritamente necessário que a sociedade promova ações de desenvolvimento sustentável que tenha por princípio a proteção ambiental, com uso racional dos recursos ambientais naturais.

Para a preservação do corpo hídrico e o ambiental as seguintes diretrizes são necessárias:

- Canalização do esgoto doméstico afim de evitar a contaminação ao longo do córrego e das nascentes ao redor do mesmo;

- Remanejo dos moradores próximo ao curso d' água com intuito de minimizar quantidade de sedimentos e de resíduos descartado ao longo do córrego;

- Proteção das nascentes oriundas na extensão do córrego que contribuem para uma maior vazão do córrego e aumenta consideravelmente o recurso hídrico;

- Interação do poder público e dos bairros vizinhos para que possa conscientizar a comunidade da importância do córrego, priorizando sua proteção eliminando o descarte incorreto e construção de moradias próxima ao córrego;

- Limpeza do córrego retirando os materiais que possam contaminar ou obstruir o curso natural da água;

- Medidas compensatórias da Mineradora mediante ao uso do recurso hídrico e pelos impactos que acarretam a comunidade.

\section{CONCLUSÕES/RECOMENDAÇÕES}

O uso irregular do solo e as ocupações desordenadas na planície de inundação e encostas dos rios, podem acarretar em processos de movimentação me massa. $\mathrm{O}$ estudo realizado ao longo desde artigo aponta que os impactos advindos do Córrego Cercadinho, incide sobre a sub bacia do Córrego Cercadinho no município de Belo Horizonte, que afeta, portanto de forma direta e indireta à população que reside a beira do córrego. A partir das análises realizadas, detectou-se várias zonas de risco nas quais as rochas e sedimentos que compõem as encostas estão, em grande parte, desagregadas.

Visto que a falta de vegetação expõe o material rochoso e faz com que fatores como a água, diminua a resistência e interfira na plasticidade e fluidez do solo. 


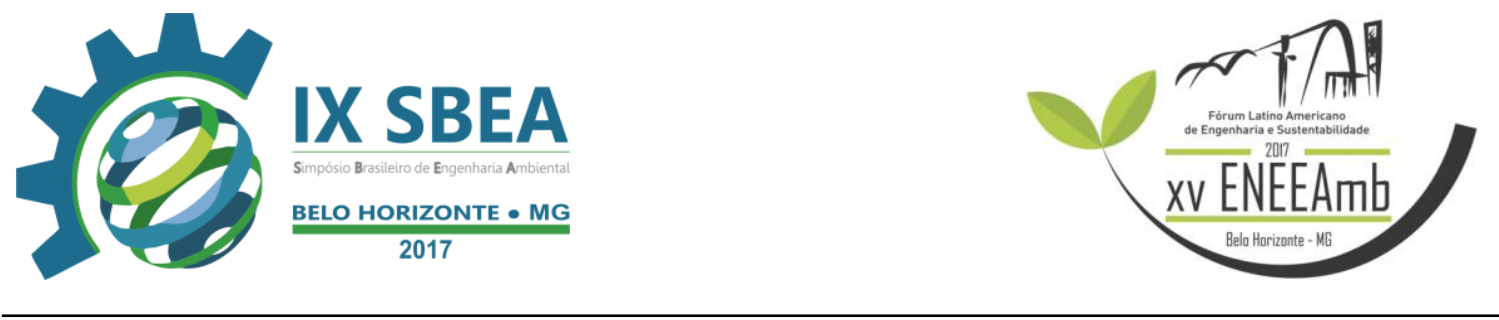

Nota-se que as áreas de encosta do Córrego Cercadinho, apresenta um risco para a população ribeira, por existir a possibilidade de catástrofes decorrentes de movimentação de massa.

De modo geral, conclui-se que o crescimento desenfreado, uso e ocupação irregular do solo ligado aos impactos causados ao curso d'água, são de responsabilidade de todos, então cabe ao poder público juntamente com a participação efetiva os moradores dos bairros Buritis e Estoril zelar pelo bem natural, contribuindo, assim para bem-estar da população e gestão da cidade. Desta forma, torna-se necessário o plantio de plantas com raízes fortes a fim de reduzir ou impedir os impactos no solo.

\section{REFERÊNCIAS BIBLIOGRÁFICAS}

BARBOSA, Bernardo Monteiro. Novos Conceitos de Engenharia Urbana: a experiência do Programa DRENURBS no Córrego Primeiro de Maio, em Belo Horizonte. Disponível em: <bmbarbosa_vers_o_final_.pdf > Belo Horizonte. Acesso em: 28 agosto 2015.

BARBOSA, Bernardo Monteiro; 2011. NOVOS CONCEITOS DE ENGENHARIA URBANA: a experiência do Programa DRENURBS. Disponível em: $<$ bmbarbosa_vers_o_final_\%20(1).pdf>. Acesso em: 30 de agosto.

IBGE. IBGE cidades, Minas Gerais, Belo Horizonte. Disponível em: $<$ http://www.cidades.ibge.gov.br/painel/painel.php?lang=\&codmun=310620\&search $=\% 7 C \% 7$ Cinfogr\%E1ficos:-dados-gerais-do-munic\%EDpio>. Acesso em 04 set 2015.

JUNIOR, Jocimar Coutinho Rodrigues. Avaliação de Impactos Ambientais no Córrego Pintado em JI-Paraná, Rondônia, disponível em: <http://www.sbpcnet.org.br/livro/65ra/resumos/resumos/1969.htm>. Acesso em: 18 novembro 2015.

Pesquisa de coliformes totais e fecais em amostras de águas coletadas no bairro Zona Sete, na cidade de Maringá - PR. Disponível em: <http://www.cesumar.br/prppge/pesquisa/epcc2011/anais/bianca_altrao_ratti\%20\% 281\%29.pdf> Acesso em: 06 out. 2015

Prefeitura de Belo Horizonte. Disponível em: $<$ http://portalpbh.pbh.gov.br/pbh/contents.do?evento=conteudo\&idConteudo=31223 \&chPlc=31223. > Acesso em: 06 out. 2015

PROJETO DE VALORIZAÇÃO DAS NASCENTES URBANAS 2012. Comitê da bacias Hidrográfica do Rio das Velhas Subcomitês das bacias hidrográficas dos ribeirões arrudas e Onça. Disponível em:

http://www.agbpeixevivo.org.br/nascentesurbanas/images/projeto/publicacoes/catal ogo.pdf . Acesso em: 30 de agosto. 


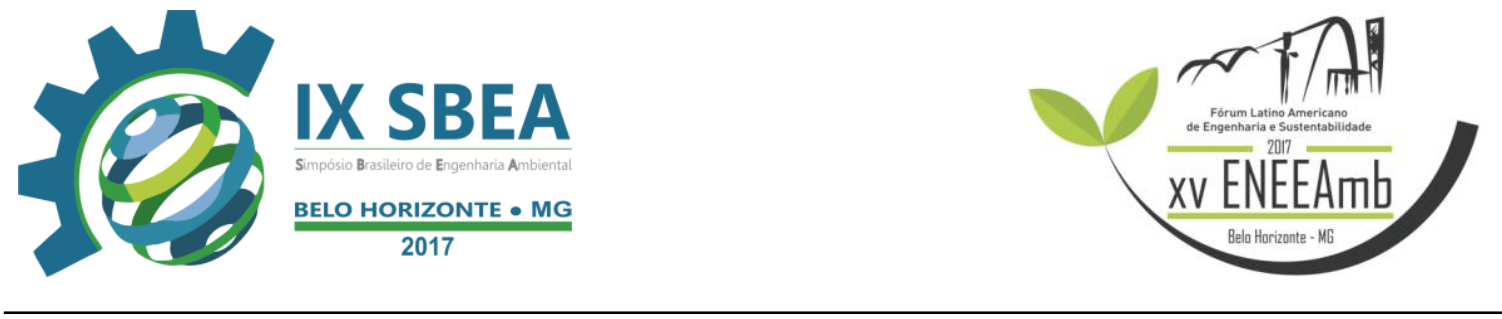

Resolução CONAMA. Disponível em:

http://www.mma.gov.br/port/conama/legiabre.cfm?codlegi=43 Acesso em: 06 out. 2015-10-07

SAAE Sorocaba - Disponível em: <http://www.saaesorocaba.com.br/downloads/concurso2010/CMl\%20003\%20\%20An\%C3\%A1lise\%20de\%20Coliformes.pdf> Acesso em: 06 out. 2015 